\title{
AGGRAVATING FACTORS OF MIGRAINE AMONG THE PATIENTS ATTENDING NEURO-MEDICINE OUTPATIENT DEPARTMENT AT TWO SELECTED TERTIARY LEVEL HOSPITAL
}

HOQUE $\mathrm{SR}^{1}$, HASAN MN ${ }^{2}$, KAFEE MA ${ }^{3}$, SHAZZAD MN ${ }^{4}$, SAHA SK ${ }^{5}$, RAHMAN MA ${ }^{6}$, KHAN $\mathrm{MMH}^{7}$, ISLAM $\mathrm{S}^{8}$, AHMED F ${ }^{9}$

\begin{abstract}
A descriptive cross-sectional type of study was conducted among the migraine patients attending the Neuromedicine department of Dhaka Medical College Hospital and Bangabandhu Sheikh Mujib Medical University to find out the aggravating factors of migraine in the year of 2006. Total number of respondents was 160. Among them 70\% were female. Majority of the patients (46.25\%) were aged between 21-30 years. Significant number of respondents (38.12\%) was housewives; followed by $28.75 \%$ were student. The main aggravating factors so far identified in this study were sleep disturbance, bright light, noise and mental or physical stress. Other aggravating factors were various types of food, oral pill, relation with menstrual cycle. Respondents also stated more than one factor. Among the female respondents 39.8\% practiced different types of contraceptive methods of which majority (82.05\%) used OCP.
\end{abstract}

Key words: Aggravating factors of migraine, family history, sleep disturbance.

J Dhaka Med Coll. 2017; 26(2) : 132-134

\section{Introduction}

Migraine is a common neurovascular disorder characterized by attacks of severe headache and autonomic and neurological symptoms. A large percentage of headache patients are suffering from migraine. ${ }^{1}$

In childhood, migraine incidence is equal in boys and girls but migraine becomes three times more common in girls than in boys during adolescence. ${ }^{2}$ Commonly starting at puberty, migraine mostly affects those aged between 35 and 45 but can trouble much younger people, including children. ${ }^{3} 25 \%$ of people with migraine will have experienced their first attack before the age of 10 and over $90 \%$ will have experienced their first attack before the age of $40 .{ }^{4}$

Migraine has a tendency to run in families, 4 out of 5 migraine sufferers have a family history of migraine. If one patient has a history of migraine, the child has a $50 \%$ chance of developing migraine and if both parents have a history of migraine, the risk jumps to $75 \% .{ }^{4}$

Worldwide prevalence of migraine is $10-12 \%$, while in Bangladesh the prevalence is $18 \%$
(Hospital based study). Among them 20\% are male and $80 \%$ are female and male-female ratio is $1: 4.5$

As migraine is not a curable, but a preventable disease, so the only way to prevent its attack is to avoid the risk factors.

Migraines develop differently among individuals with a varied combination of symptoms. For this reason, migraines are often undiagnosed in the general population.

\section{Materials and Methods:}

This was a descriptive type of cross-sectional study conducted at Neuromedicine department of Dhaka Medical College Hospital (DMCH) and also at the out-patient department of Bangabandhu Sheikh Mujib Medical University (BSMMU). Study population was all the patients having migraine as diagnosed by the physician attending at the outpatient department of $\mathrm{DMCH}$ and BSMMU. Sample was taken purposively and final sample size was 160 . A pretested semi-structured questionnaire was used as research instrument. Data were collected by face to face interview. Data were

1. Dr. Syeda Rumana Hoque, Assistant Professor, Department of Community Medicine, Dhaka Medical College, Dhaka.

2. Dr. Md. Nazmul Hasan, Assistant Professor, Medicine, BSMMU, Dhaka

3. Dr. Md. Abdullahhel Kafee, Assistant Professor Medicine, Kurmitola General Hospital, Dhaka

4. Dr. Nahiduzzaman Shazzad, Medical Officer, Rheumatology, BSMMU, Dhaka

5. Dr. Sanjoy Kumar Saha, Associate Professor, Ad-din Medial College Hospital, Dhaka

6. Dr. Md. Abdur Rahman, Junior. Consultant, Department of Medicine, Jinjira 20 beded Hospital, Keraniganj, Dhaka

7. Dr. Mohammed Masudul Hassan Khan, Medical Officer, 250 Beded Hospital, Shyamoli, Dhaka

8. Dr. Sadia Islam, Assistant Professor of Medicine, Delta Medical College \& Hospital, Dhaka

9. Dr. Fatema Ahmed, Associate Professor, Department of Critical Care Medicine, BIRDEM, Dhaka

Correspondence: Dr. Syeda Rumana Hoque, Assistant Professor, Dept. of Community Medicine, Dhaka Medical College, Dhaka 
summarized and presented by using scientific calculator and excel program 98.

\section{Result:}

The study was carried out among 160 diagnosed migraine patients. Male female ratio was 3:7 and majority was in the age group of 21 to 30 years with mean 30.23 and the SD was 10.34 years. About $12 \%$ respondents were illiterate. Regarding occupation most frequent were housewife $(38 \%)$ and students $(29 \%)$. Most of the cases $(61 \%)$, duration of sufferings was $<5$ years, very few $(4 \%)$ was suffered for $>25$ years. More than half $(54 \%)$ of the respondents had family history of migraine. Regarding aggravating factors, multiple answers were common. Sleep disturbance, bright light, noise and stress were common findings.

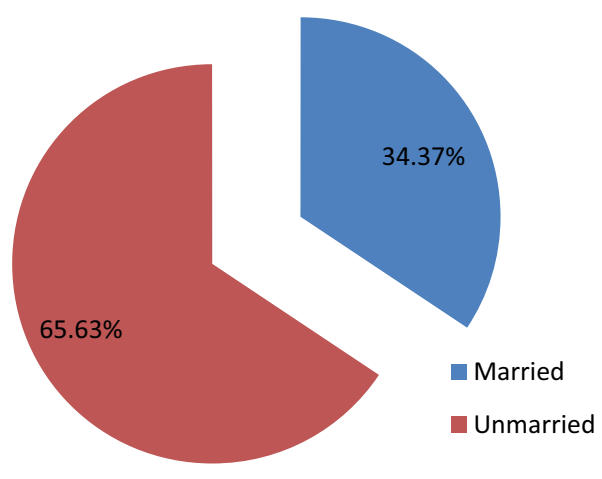

Fig.-1: Distribution of respondents by marital status

Table-I

Age distribution of the respondents

\begin{tabular}{lccc}
\hline $\begin{array}{l}\text { Age } \\
\text { (in year) }\end{array}$ & Frequency & $\begin{array}{c}\text { Percentage } \\
(\%)\end{array}$ & Statistic \\
\hline$<20$ & 23 & 14.35 & Mean $=30.23 \mathrm{yr}$ \\
$21-30$ & 74 & 46.26 & $\mathrm{SD}=+10.34$ \\
$31-40$ & 36 & 22.50 & \\
$41-50$ & 25 & 15.63 & \\
$>51$ & 2 & 1.26 & \\
\hline Total & 160 & 100 & \\
\hline
\end{tabular}

Table-II

Family H/O migraine among the respondents

\begin{tabular}{lcc}
\hline $\begin{array}{l}\text { Family H/O } \\
\text { migraine }\end{array}$ & Frequency & $\begin{array}{c}\text { Percentage } \\
(\%)\end{array}$ \\
\hline Present & 87 & 54.37 \\
Absent & 73 & 45.63 \\
\hline Total & 160 & 100 \\
\hline
\end{tabular}

Table-III

Aggravating factors for migraine

\begin{tabular}{lc}
\hline Predisposing factors* & Frequency \\
\hline Sleep disturbance & 132 \\
Bright light & 118 \\
Loud noise & 107 \\
Stress & 103 \\
Hypertension & 42 \\
Relation with food & 33 \\
OCP & 32 \\
\hline
\end{tabular}

${ }^{*}$ Multiple response

Table-IV

Relation of migraine with menstruation( $n=98)$

\begin{tabular}{lcc}
\hline $\begin{array}{l}\text { Relationship with } \\
\text { menstruation }\end{array}$ & Frequency & $\begin{array}{c}\text { Percentage } \\
(\%)\end{array}$ \\
\hline Yes & 32 & 32.65 \\
No & 66 & 67.35 \\
\hline Total & 98 & 100 \\
\hline
\end{tabular}

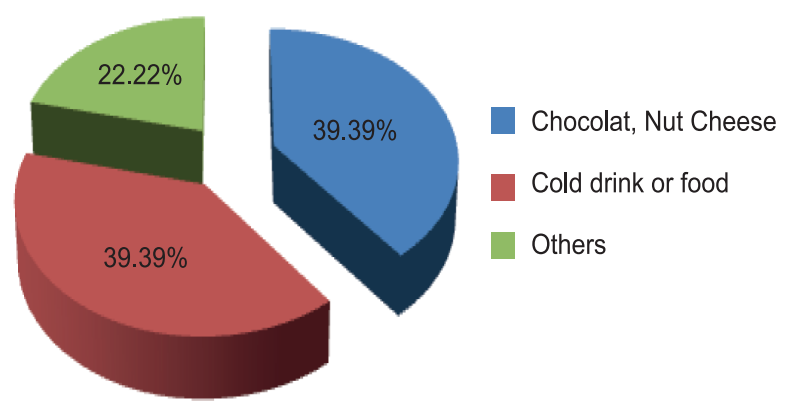

Fig.-2: Types of food associated with migraine 


\section{Discussion}

Among them about $65 \%$ respondents were married. Of the total respondents $70 \%$ were female and the male female ratio was found about 3:7. According to WHO report March 2004 the prevalence rate was 2-3 times higher in women than those in men. Higher rate in women were hormonally driven.$^{3}$

In our study most of the respondents (68.75\%) found in the age group of 21-40 years. Only a few $(14.35 \%)$ were in the age group of 20 years or less and $16.88 \%$ were more than 40 years of age. Other study suggests that over $90 \%$ experienced their first attack before the age of 40 . With the increasing age attack rate usually decreases . ${ }^{4}$

Our study showed that highest percentage $(38 \%)$ of migraineurs complained of having attack at any time, secondly $25 \%$ respondents had their pain usually occurring in the morning.

When we searched for relationship of migraine with family history, we found that $54 \%$ of the respondents had a family history of migraine. Migraine have a tendency to run in families, 4 out of 5 migraine sufferers had a family history . 4

Considering the aggravating factors for the migraine among the respondents we found multiple responses, i.e. most of the respondents stated about having several risk factors. Majority of the respondents (132) complained about sleep disturbance. The other factors according to frequency of response were bright light, loud noise, stress, hypertension, relation with food and oral contraceptive pill.

Of the respondents who had relation with food $39.39 \%$ had problem with chocolate/nut/ cheese, $39.39 \%$ had problem with various types of food like beef, tea, banana etc. and $21.22 \%$ had problem with cold drink. According to Maurice Victor certain dietary items particularly chocolate, cheese, fatty foods, oranges, tomatoes, tyramine containing food, especially wine, alcohol provoke and attack in some various persons .6 Type of food triggering migraine may vary from other studies due to different food habit of the people of our country.

Among the female respondents, 32.65\% had relation with menstruation. Among them $75 \%$ of women felt their problem during the menstrual phase, which can be marked as 'true menstrual migraine'. This finding is consistent with the text of Walter and Robert which stated that at least $25 \%$ of female migraineurs had relation menstruation. Migraine attacks occur throughout the cycle but increased in frequency and intensity at the time of menstruation. This association found up to $60 \%$ of female migraineurs. Among them true menstrual migraine is associated with up to $7 \%$ of female migraineurs. Premenstrual migraine can occur in few women.$^{7}$ In our study only $18.75 \%$ women had premenstrual migraine.

Among the $39.8 \%$ of reproductive age group of woman, $32(82.05 \%)$ used oral contraceptive pill. Our result is also consistent with World Health Organization report, March 2004 which said oral contraceptive pills are the main precipitants of severe migraine.$^{3}$

\section{Conclusion:}

Migraine is not only a severe painful disease but also a disabling one and people suffer from it for long duration. Majority of the migraineurs complained of several precipitating factors. We suggest to prevent the aggravating factors, building awareness among the people about migraine and its precipitating factors. These would be the best method to help thousands of migraineurs who are around us.

\section{References:}

1. Ferrari MD. Migraine. Lancet 1998: 351:1043-51

2. Breslau N, Rasmussen BK. The impact of migraine. Department of Psychiatry, Henry Ford Hospital, Detroit, Michigan and Department of Neurology, Hilleriod County Hospital, Denmark. [cited September 2006].Available from: www.nebi.nlm. nih.gov/entrez ,

3. WHO. Headache disorder. March 2004

4. Epidemiology of Migraine. [viewed on September 2006] Available from: www.nebi.nlm.nih.gov/entrez,

5. Mohammad QD.Headache disorder: Bangladesh perspective. An unpublished study of Dr. Quazi Deen Mohammad, Head of the Deptt. of Neuromedicine, Dhaka Medical College Hospital.

6. Victor M, Ropper AH. Headache and other craniofacial pains. In:Foltin J, Nogueira I, Edmonson KG, Sheinis LA eds. Adams and Victors Principles of Neurology, $8^{\text {th }}$ edition NY: McGrew Hill Medical Publishing division; 2005.147-155

7. BJ Christopher, JC David, FM Cutrer, WD David, G Ivan, WS Jerry. Headache and other craniofacial pain. In: GB Walter, BD Robert, MF Gerald, J Joseph,editors. Neurology in Clinical Practice, vol.2; $5^{\text {th }}$ edition. USA:Elsevier; p.2011- 2062. 